\title{
Circular-Looking Makes Green-Buying: How Brand Logo Shapes Influence Green Consumption
}

\author{
Liying $X u^{1,2} \oplus$, Feng $\mathrm{Yu}^{3, *}$ and Xiaojun Ding ${ }^{1}$ \\ 1 School of Humanities and Social Sciences, Xi'an Jiaotong University, Xi'an 710049, China; \\ xuliying@stu.xjtu.edu.cn (L.X.); xiaojunding@xjtu.edu.cn (X.D.) \\ 2 Department of Social and Behavioural Sciences, City University of Hong Kong, Hong Kong, China \\ 3 Department of Psychology, School of Philosophy, Wuhan University, Wuhan 430072, China \\ * Correspondence: psychpedia@whu.edu.cn
}

Received: 22 January 2020; Accepted: 26 February 2020; Published: 27 February 2020

\begin{abstract}
Despite the development of green products, convincing consumers to engage in green consumption is still a difficult task. This research attempts to help solve this problem from the perspective of brand logo design. Specifically, this research explores how circular and angular logo shapes influence green consumption. Three studies provide support for our basic prediction that a circular (vs. angular) logo is more effective in promoting green consumption. Self-construal plays a mediating role in this mechanism. However, the logo shape effect disappears when consumers are primed with high sense of power. When taken together, this research not only has theoretical contributions to green consumption and visual marketing, it also provides practical implications for firms manufacturing green products.
\end{abstract}

Keywords: brand logo design; shape; green consumption; self-construal; power

\section{Introduction}

Faced with serious environmental problems that threaten the environment and human life, an increasing number of people are concerned more about environmental issues and sustainable development. In the field of marketing, many companies are also interested in developing eco-friendly products [1]. For example, Toyota Motor Company is working on developing a new kind of vehicles that will greatly reduce $\mathrm{CO}_{2}$ emissions [2]. However, in spite of companies' effort to develop green products, convincing consumers to engage in green consumption is still quite difficult [3]. Hence, learning more about the factors that contributes to green consumption is of great significance.

To date, most of the research on green consumption has explored the influential factors of green consumption from a consumer-level perspective [4]. For example, Kim and Choi [5] demonstrated that collectivism impacts consumers' beliefs about consumer effectiveness, which in turn impacts their green consumption. In addition, [6] found that consumers' green consumption is influenced by their green self-identity, peer influence, and past green buying experiences. However, few studies have explored green consumption from a perspective of companies' marketing strategies, especially the effect of brand logo design. Brand logos are important visual brand elements that influence the financial performance of a brand [7]. Does brand logo design have an effect on green consumption? If yes, which kind of brand logos can most effectively convince consumers to engage in green consumption? Prior research has barely answered these questions.

Therefore, the present research attempts to answer these questions from the perspective of brand logo shapes. Specifically, we examine the effect of angular and circular logo shapes on green consumption. In addition, the study also investigates the mediating role of self-construal and the moderating role of power on the effect of brand logo shapes. Our research not only contributes to 
extending previous studies of brand logo design to the field of green consumption, it also deepens the understanding of mechanisms underlying green consumption. Importantly, since we tried to investigate the mechanism underlying green consumption from a psychological perspective, our research also contributes to the Psychology of Sustainability and Sustainable Development, which is a new research area developed by Di Fabio [8-10].

\subsection{Logo Shapes and Green Consumption}

Brand logos, as visual representations of brands, have been demonstrated to play a significant role in brand performance [7]. Specifically, findings in marketing provide evidence that brand logo design has many downstream effects, such as brand preference [11], brand awareness [12], purchase intention [13,14] and even actual food intake [15].

A brand logo usually contains multiple visual design elements, such as shape [16,17], color [18-20], and typeface [21]. Prior research has shown that these different brand logo elements are perceived by consumers in terms of not only their technical properties but also their symbolic associations $[14,22]$. Symbolic associations refer to abstract properties that brands do not objectively have but implicitly convey to consumers $[17,23]$, and they have been found to influence brand evaluations, consumption intentions, as well as consequent behaviors $[14,24,25]$. People exposed to Apple logos, for instance, behave more creatively compared with people exposed to IBM logos [26].

Although brand logos have innumerable different shapes, generally speaking, logo shapes can be classified as angular, circular, or a combination of both [17]. Angular shapes are characterized by sharp angles and straight lines, while circular shapes are typically curved. The empirical marketing literature suggests that angular and circular logo shapes can elicit different symbolical associations such as hardness and softness [17]. More importantly, studies have shown that angular and circular shapes are related to social perceptions. While angular shapes activate associations with traits such as energetic and tough, circular shapes activate associations with traits such as friendly and harmonious [27]. In addition, compared with angular shapes, circular shapes elicit more pro-social associations such as cooperative and sympathetic personalities [25].

Broadly speaking, green consumption is not only a form of pro-environmental behavior but also a form of pro-social behavior [28]. While pro-social behaviors can be defined at different levels [29], we broadly define pro-social behaviors as behaviors intended to benefits others. Consistent with this definition of pro-social behaviors, green consumption can be regarded as a form of pro-social behavior that benefits the environment. Given the facts that circular (vs. angular) logo shapes can activate pro-social symbolical associations and green consumption is a form of pro-social behavior, it is reasonable to predict that, compared with an angular logo, a circular logo will have a more favorable impact on green consumption. Hence, we propose the following main hypothesis:

Hypothesis 1 (H1). When exposed to a circular (vs. angular) logo, consumers are more inclined to green consumption.

\subsection{The Mediating Role of Self-Construal}

Self-construal refers to how people perceive their relationship with others [30]. According to Markus and Kitayama [30], Western culture promotes an independent self-construal, while East Asian culture encourages a more interdependent self-construal. People with independent self-construal see themselves as independent, bounded, and autonomous, and tend to value uniqueness, independence, and individual accomplishments; their actions arise from internal reasons such as personalities and abilities. In contrast, individuals with interdependent self-construal see themselves as a part of groups, as interconnected with others, and tend to emphasize connectedness, conformity, and harmony with other people; their behaviors are usually influenced by social contextual factors. Although independent self-construal is dominant in individualistic cultures and interdependent self-construal is dominant in collectivistic cultures [31], self-construal is susceptible to situational factors such as cultural 
symbols [32] and collective pronounces (e.g., "we", "us", "I", and "me"). In addition, temporary priming of independent and interdependent self-construal has been shown to influence cognition and consequent behaviors [33,34].

Similar to the distinction between independent and interdependent self-construal, angular and circular shapes are likely to elicit different symbolical associations oriented to the self or others. Empirically, studies have shown that an angular seating arrangement induces people's need for uniqueness, while a circular seating arrangement induces people's need for belongingness [35]. In addition, past research has provided more direct evidence of the relationship between self-construal and various shapes (i.e., angular and circular shapes). Zhang et al. [16] found that individuals with an independent self-construal prefer angular shapes, whereas individuals with an interdependent self-construal find circular shapes more attractive. From a perspective of re-designing logos, Walsh, Winterich, and Mittal [36] suggest that rounded (i.e., circular) logos are congruent with consumers' interdependent self-construal, whereas angular logos are congruent with consumers' independent self-construal.

Interdependent self-construal is associated with green consumption, since they are both pro-social behaviors. The empirical cultural psychological literature suggests that, compared with individuals with independent self-construal, individuals with interdependent self-construal attach more importance to social public interests [37] rather than their personal interests [38]. Obviously, interdependent self-construal is closely related to a more other-oriented and pro-social tendency [39]. Green consumption, as a form of pro-social behavior, benefits the environment for everyone in society [28]. Prior environmental research has shown that people with interdependent self-construal tend to express more environmental concerns than those with independent self-construal [40]. In addition, Chuang, Xie, and Liu [41] demonstrated that interdependent self-construal increases pro-environmental preferences, which also directly revealed the relationship between self-construal and pro-environmental choices. Taken together, we propose the following hypothesis:

Hypothesis 2 (H2). The effect of logo shapes on green consumption is mediated by self-construal, such that exposure to a circular logo induces an interdependent self-construal, which in turn increases green consumption.

\subsection{The Moderating Role of Sense of Power}

Traditionally, power is defined as asymmetric control over valuable resources, goods, and rewards in social relationships [42,43]. However, power is not only the actual control over resources but also a psychological state that reflects people's perception of their ability to influence others [44]. In addition, sense of power can be either a relatively stable psychological state or a temporary feeling, thus different senses of power can be primed [45].

As a ubiquitous and influential factor in social relationships, power has been found to influence an individual's affect, motivation, information processing, and social behaviors [42]. In terms of consumption, past research has shown that power has a number of effects on consumers' perceptions and behaviors such as brand choice, purchase intention, responses to prices, as well as attitudes towards others and themselves [46]. In particular, research has demonstrated that power affects consumers' orientation to focus on themselves or others [47]. Specifically, consumers with high power spend more money on themselves, while consumers with low power spend more money on others [47]. In addition, compared with consumers with low power, consumers with high power tend to focus on their own thoughts [48], and they are less influenced by other people's attitudes [49]. These studies suggest that various levels of power (i.e., high power vs. low power) lead to different orientations (self-oriented vs. other-oriented), and different orientations involve how consumers allocate their resources to themselves versus others. To be specific, consumers with high power tend to be self-oriented-they care more about themselves and purchase for their own benefits-whereas consumers with low power tend to be other-oriented; they care more about others and purchase for others' benefits. 
Since green consumption is a form of pro-social behavior intended to benefit others and the environment, it is reasonable to assume that power will moderate the effect of logo shapes on green consumption. Powerlessness will encourage consumers exposed to a circular logo to continue preferring green consumption because it contributes to orienting them towards focusing on others and environment. In contrast, powerfulness will orient consumers to focusing more on themselves, thus diminishing the effect of logo shapes on green consumption.

Hypothesis 3a (H3a). The effect of logo shapes on green consumption is attenuated when consumers have a high sense of power.

Hypothesis $\mathbf{3 b} \mathbf{( H 3 b )}$. Consumers exposed to a circular logo (angular logo) are more inclined to green consumption when consumers have a low sense of power.

\section{Study 1: The Relationship between Logo Shapes and Green Consumption}

Study 1 aimed at exploring whether circular and angular logo shapes influence green consumption. Consistent with our literature review and basic hypothesis, we predicted that, compared with an angular logo, a circular logo would have a more favorable impact on green consumption.

\subsection{Method}

\subsubsection{Participants and Design}

A total of 123 participants were recruited online to complete the study through Qualtrics. Data from one participant who did not pass a manipulation check were eliminated from further analyses. The final sample included 122 participants ( 60 males, 62 females, $M_{\text {age }}=29.71, S D=9.56$ ). We randomly assigned participants to a one-way between-subjects design that contained two logo shape conditions: circular and angular logo.

\subsubsection{Procedures}

In order to avoid potential confounding influences of participants' brand familiarity and preference, we chose a virtual household cleanser manufacturer named LHA and two virtual household cleansers. First, participants were shown a brief introduction of LHA, which contained a sentence "LHA is a manufacturer specializing in different kinds of household cleansers" and a picture of LHA's logo. We used circular and angular logos developed by Jiang et al. [17], and we added "LHA" in various fonts at the bottom of different logo (see Figure 1). Following exposure to the introduction, participants were asked to imagine that they were going shopping for a household cleanser. They were presented with two options: one was an industrial strength household cleanser that was more effective (e.g., "kills $99.9 \%$ of germs"), whereas the other one was a natural household cleanser that was more eco-friendly (e.g., "made from biodegradable nontoxic materials") [28]. The prices of two household cleansers were equal (42 RMB). Then, participants were asked the following question: "If you need a household cleanser, which of these two products would you buy?" On the next web page of the experiment, participants were asked to recall and briefly describe the logo shape of LHA for a manipulation check. Finally, demographics data including age and gender were collected.

\subsection{Results}

In total, $56.5 \%$ of participants chose the green household cleanser in the circular logo condition, whereas $38.3 \%$ of participants chose it in the angular logo condition, $\chi^{2}(1, \mathrm{~N}=122)=4.01, p=0.045$. This finding supported H1. 


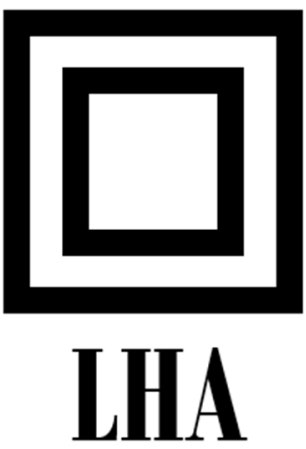

(a)

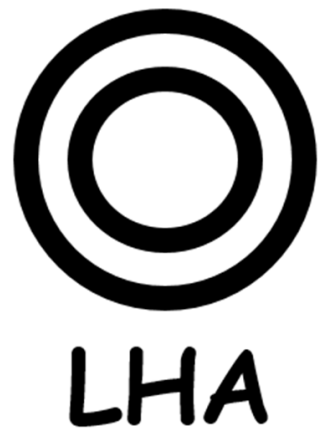

(b)

Figure 1. Brand logos used in Study 1: (a) angular logo; (b) circular logo.

\section{Study 2: The Mediating Role of Self-Construal}

Study 2 had three objectives. The first one was to replicate the main finding of Study 1 in another sample. Second, in order to improve the robustness and the validity of the logo shape effect, we used various circular and angular logos as well as different products. Thirdly, we investigated the mediating effect of self-construal on the relationship between the logo shape effect and green consumption.

\subsection{Method}

\subsubsection{Participants and Design}

In total, 163 undergraduates (100 males, 63 females, $M_{\text {age }}=19.36, S D=1.17$ ) participated in this study through Qualtrics for course credit. All participants passed the manipulation check and completed the whole study. As with Study 1, Study 2 also employed a one-way between-subjects design that manipulated the logo shapes (logo shape: circular logo vs. angular logo).

\subsubsection{Procedures}

Participants were firstly exposed to a brief introduction of a battery brand. We kept the same brand name LHA used in Study 1 because it was a virtual and meaningless brand name without confounding influences. The introduction of LHA used in Study 2 contained a sentence "LHA is a manufacturer specializing in different kinds of batteries" and a picture of LHA's logo [17] (see Figure 2). Then, participants were asked to imagine that they were going shopping for a battery and considering the choice between two different batteries: one was lithium battery better in performance (e.g., "perform in the most extreme temperatures"), and the other was more environmentally friendly and recyclable (e.g., "easiest battery to recycle") [28]. The prices of two batteries were equal (8 RMB). After reading the descriptions of two batteries, participants were asked to report their purchase intention by answering "If you need a battery, which of these two products would you buy?" One represented lithium battery and 7 represented the eco-friendly battery. As in Study 1, participants were asked to recall and briefly describe the logo shape of LHA for a manipulation check. Next, we used a self-construal scale developed by Singelis [31] to measure the self-construal of participants. This scale contained 15 items related to independence ( $\alpha=0.84$; e.g., "I feel it is important for me to act as an independent person") and 15 items related to interdependence ( $\alpha=0.84$; e.g., "I will sacrifice my self interest for the benefit of the group I am in"). The items were rated on a 7-point scale ranging from $1=$ Strongly Disagree to $7=$ Strongly Agree. Finally, demographics data including age and gender were collected. 


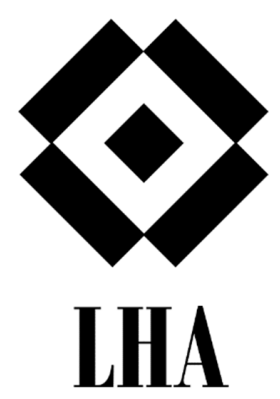

(a)

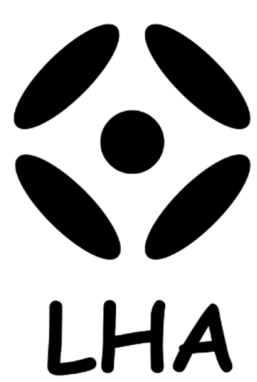

(b)

Figure 2. Brand logos used in Study 2: (a) angular logo; (b) circular logo.

\subsection{Results}

We estimated a one-way between-subjects analysis of variance (ANOVA) with condition as the between-subjects manipulated factor and green consumption as the dependent variable. Results showed that participants' purchase intention of green battery was greater in the circular logo condition $(M=4.73, S D=2.43,95 \%$ CI $[4.22,5.24])$ than in the angular logo condition $(M=3.30, S D=2.36,95 \%$ CI $[2.75,3.85]), F(1,161)=14.26, p<0.001$, partial $\omega^{2}=0.082$. This finding supports H1.

We calculated the means of independence and interdependence subscales, and we got the final score of self-construal through the independence score minus the interdependence score. Higher scores indicated greater independence, whereas lower scores indicated greater interdependence.

To test whether self-construal mediates the effect of logo shape on green consumption, we conducted a bootstrap analysis with 5000 samples [50,51] using logo shape condition as the independent variable (angular $\operatorname{logo}=0$; circular $\operatorname{logo}=1$ ), self-construal as the mediator, and green consumption as the dependent variable. The $95 \%$ Cis did not include zero, indicating that self-construal mediates the effect of logo shape on green consumption (indirect effect $=0.18, S E=0.11,95 \%$ CI $[0.02,0.45]$ ). Controlling for self-construal, the direct effect of logo shape on green consumption was significant (direct effect $=1.25, S E=0.39,95 \%$ CI $[0.49,2.01]$ ), suggesting partial mediation. Results of the regression showed that self-construal partially mediated the effect of logo shape on green consumption (see Figure 3), therefore providing support for H2.

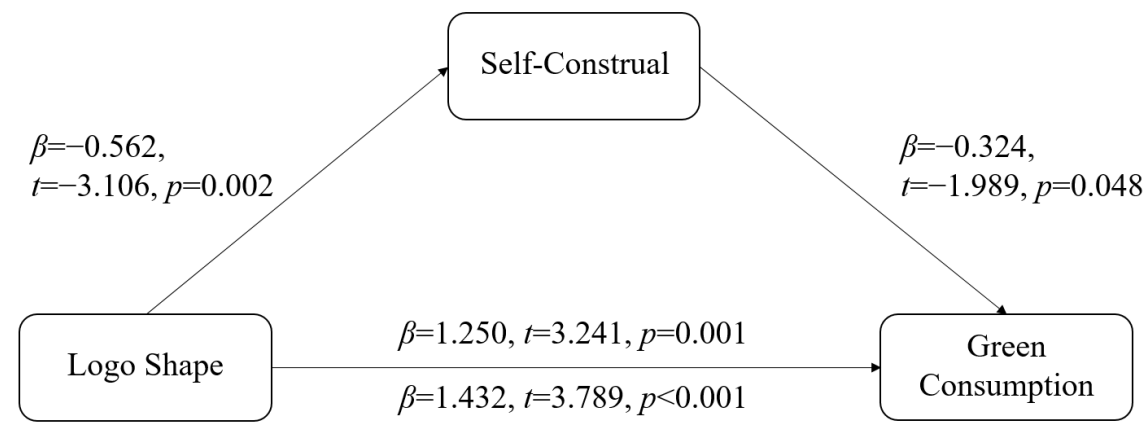

Figure 3. The mediating effect of self-construal.

\section{Study 3: The Moderating Role of Power}

The main objective of Study 3 was to test whether primed sense of power would moderate the relationship between the logo shape effect and green consumption (see Figure 4). We expected that when participants were primed with low sense of power, they would prefer to buy green products in circular logo condition (vs. angular logo condition), but when participants were primed with high sense of power, there would be no significant difference of preference for green products between two logo shape conditions. 


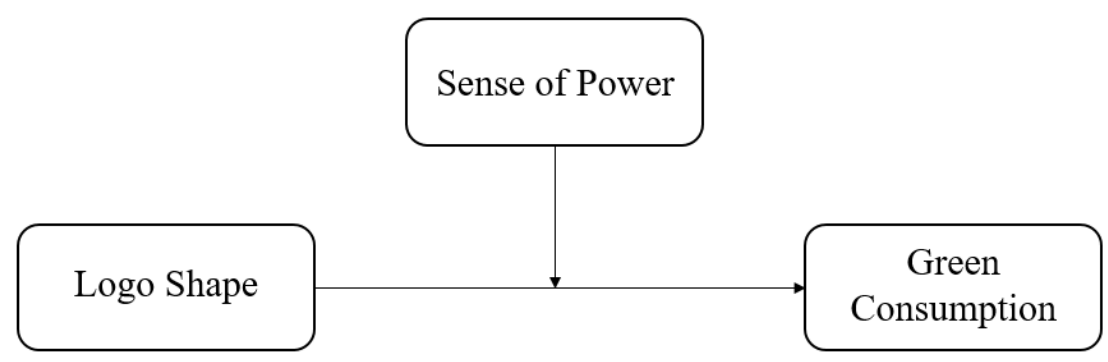

Figure 4. Conceptual framework of Study 3.

\subsection{Method}

\subsubsection{Participants and Design}

A total of 302 undergraduates participated in this study through Qualtrics for course credit. Data from 3 participants who did not pass a manipulation check or complete the study were eliminated from further analyses. The final sample included 291 undergraduates (146 males, 145 females, $M_{\text {age }}=$ $19.01, S D=1.52$ ). We randomly assigned participants to a 2 (power: high vs. low) $\times 2$ (logo shape: circular logo vs. angular logo) between-subjects design.

\subsubsection{Procedures}

Firstly, participants were asked to recall a particular event in which they had high power or low power [45] and to write the event as detailed as possible. As a manipulation check, we then measured participants' sense of power using Anderson and Galinsky's Sense of Power scale [52]. The scale consisted of 8 items such as "I can get people to listen to what I say". Participants were asked to rate their agreement with these items on a 7-point scale ranging from $1=$ Strongly Disagree to $7=$ Strongly Agree. Four items were reverse-scored, and higher scores indicated higher sense of power. The Cronbach $\alpha$ of this scale in the present study is 0.80 .

Secondly, participants were shown a brief introduction of a backpack brand. We chose a new virtual brand XUYU, and its introduction contained a sentence "XUYU is a manufacturer specializing in different kinds of backpacks" and a picture of XUYU's logo [14] (see Figure 5).

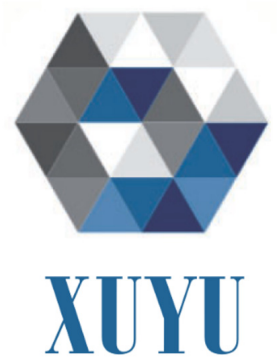

(a)

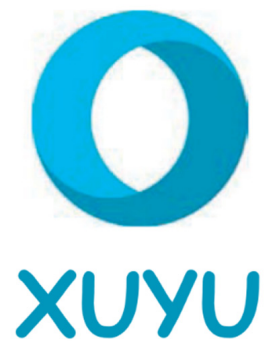

(b)

Figure 5. Brand logos used in Study 3: (a) angular logo; (b) circular logo.

Finally, we asked participants to imagine that they were going shopping for a backpack and considering to choose between two different backpacks: one was strength backpack better in quality (e.g., "water-resistant coating"), whereas the other backpack was more environmental-friendly and recyclable (e.g., "made from 100\% organic fibers") [28]. The prices of two backpacks were equal (182 RMB). Following exposure to descriptions of two backpacks, participants reported their purchase intention by answering "If you need a backpack, which of these two products would you buy?" One represented the strength backpack and 7 represented the eco-friendly backpack. As in Study 
1 and Study 2, participants were asked to recall and briefly describe the logo shape of XUYU for a manipulation check. In addition, participants reported their age and gender.

\subsection{Results}

\subsubsection{Manipulation Check}

A 2 (power: high vs. low) $\times 2$ (logo shape: circular logo vs. angular logo) between-subjects ANOVA using sense of power as the dependent measure revealed only a main effect of power. Participants in the high power condition reported greater sense of power $(M=4.66, S D=0.73,95 \% \mathrm{CI}$ $[4.54,4.78])$ than did participants in the low power condition $(M=4.30, S D=0.98,95 \% \mathrm{CI}[4.14,4.46])$, $F(1,287)=12.22, p=0.001$, partial $\omega^{2}=0.041$.

\subsubsection{Hypothesis Testing}

A 2 (power: high vs. low) $\times 2$ (logo shape: circular logo vs. angular logo) between-subjects ANOVA using green consumption as the dependent measure revealed a significant effect of power $\left(F(1,287)=4.60, p=0.033\right.$, partial $\left.\omega^{2}=0.016\right)$, a significant effect of logo shape $(F(1,287)=5.31, p=$ 0.022 , partial $\left.\omega^{2}=0.018\right)$, and a significant interaction $\left(F(1,287)=4.40, p=0.037\right.$, partial $\left.\omega^{2}=0.015\right)$. As we expected, a simple effect test revealed that when participants were primed with low sense of power, participants in the circular logo condition reported greater purchase intention for green product $(M=3.44, S D=2.11,95 \% \mathrm{CI}[3.01,3.87])$ than did participants in the angular logo condition $(M=2.47$, $S D=1.86,95 \%$ CI $[2.03,2.91]), F(1,287)=9.74, p=0.002$, partial $\omega^{2}=0.033$ (see Figure 6). In contrast, when participants were primed with high sense of power, there was no significant difference between the circular logo condition $(M=2.50, S D=1.75,95 \% C I[2.05,2.95])$ and angular logo condition $(M=$ $2.46, S D=1.80,95 \% \mathrm{CI}[2.03,2.88])$ on green consumption $(F<1)$.

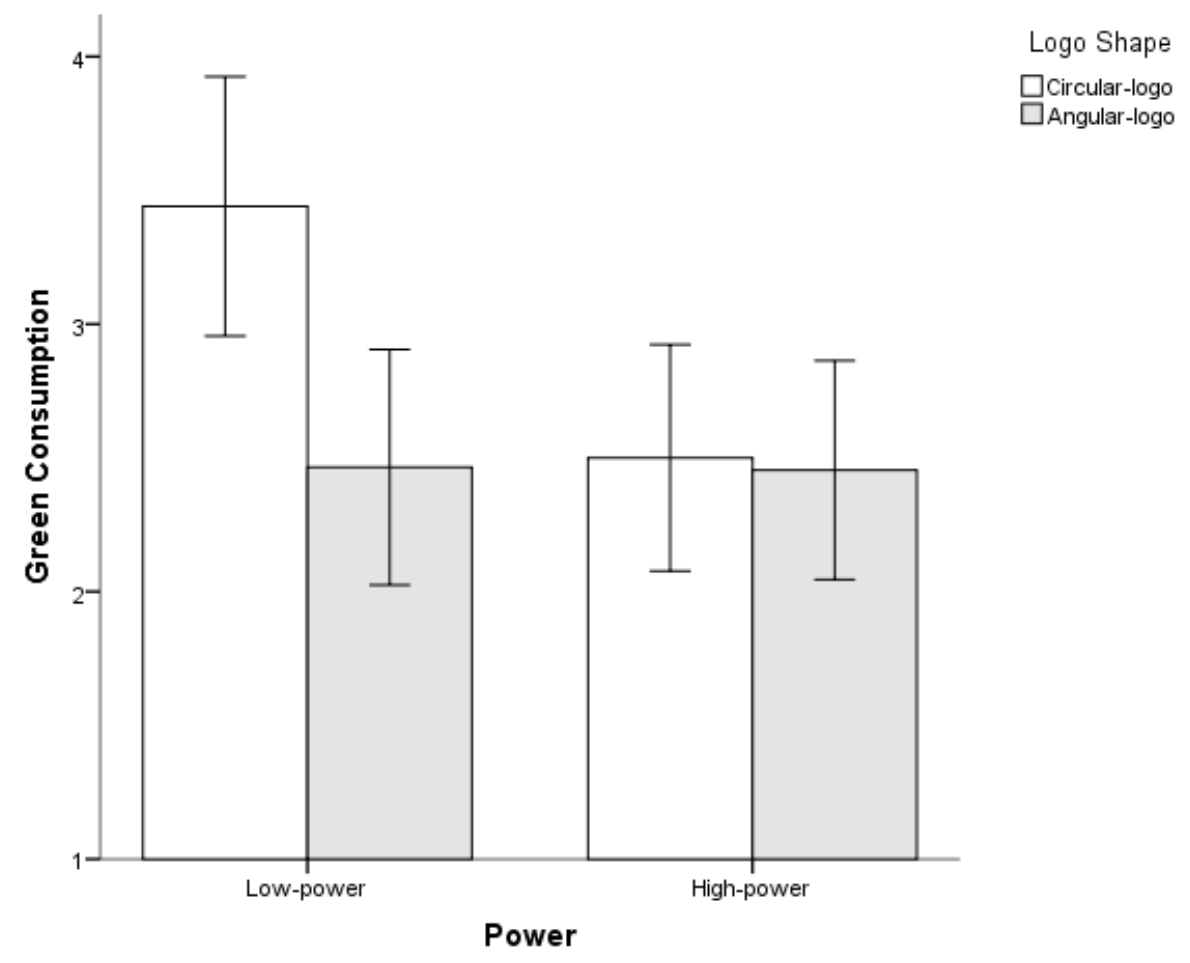

Figure 6. The moderating effect of power. 


\section{Conclusions and Discussion}

\subsection{Conclusions}

The current research focused on the relationship of logo shapes and green consumption. Results of three studies reported in this article showed that mere angularity/circularity of logos could influence green consumption. Using different angular and circular logos as well as various products, we provided empirical evidence that consumers exposed to a circular (vs. angular) logo were more inclined towards green consumption (supporting H1). In addition, Study 2 further demonstrated that this effect was mediated by self-construal (supporting H2). In Study 3, we found that power was a moderating fact of this effect (supporting H3a and H3b). Specifically, when consumers were primed with high sense of power, there was no significant difference between green consumption tendencies of consumers in angular and circular logo conditions, which indicated that the effect of logo shapes on green consumption was diminished by sense of power (supporting H3a). However, when consumers were primed with low sense of power, consumers in circular logo condition (vs. angular logo condition) were more willing to make a pro-environmental consumption choice (supporting H3b).

\subsection{Theoretical Contributions}

Our findings make contributions in several areas. First, our research demonstrates the power of logo shape design to subtly influence green consumption, which extends previous literature of logo shapes to the field of sustainability. The effect of visual shapes on people's judgments has been documented by consumer and psychology researchers. While prior research on this topic has focused on consumers' judgments such as aesthetic preference [16], brand attribute judgment [17], and personality judgment [25], our research attempts to further identify a specific product choice (i.e., green consumption) and to investigate whether it can be influenced by mere visual shapes.

Secondly, the present research adds to a growing body of literature that investigates self-construal and pro-environmental behaviors in a number of ways. We explored the underlying mechanism responsible for the effect of logo shapes on green consumption and found the mediating role of self-construal. Self-construal is an important cross-cultural psychological conception. Therefore, our research is an attempt to apply psychological processes to the science of sustainable development and to probe into environmental sustainability from a trans-disciplinary perspective. This coincides with the goal of the Psychology of Sustainability and Sustainable Development [8-10] as well as Psychology of Harmonization [53]. Prior work has demonstrated the impact of self-construal on pro-environmental behaviors [40]; our research extends this finding by showing that self-construal may serve as a mediator between logo shapes and green consumption. In addition, our results are consistent with previous research that has demonstrated that an interdependent self-construal gives rise to prosocial behaviors [39]. Green consumption is regarded as a form of prosocial behavior because it is a kind of voluntary behavior intended to achieve environmental benefits. Therefore, explaining the effect of logo shapes on green consumption from the perspective of self-construal further proves the relationship between self-construal and prosocial behaviors. Moreover, while previous literature has focused on documenting the effect of self-construal on verbal information processing, little research has been done to examine the relationship between self-construal and visual information processing [16]. In this context, our studies represent an attempt to fill this research gap.

Thirdly, our research advances the literature on green consumption by providing a boundary condition for the impact of logo shapes on green consumption. By examining the role of sense of power in moderating the effect of logo shapes, we provided evidence that the effect will be diminished when consumers have high sense of power. This finding is consistent with prior research that has demonstrated that high-power consumers are less inclined to green consumption compared with low-power consumers [54]. In addition, marketing research has suggested that consumers prefer powerful brands when their logo is placed high on the brands' packaging [11], which indicates that consumers intuitively link conception of power with logo's height. Similarly, in the present research, 
we focused on consumers' sense of power and confirmed its moderating role in the effect of logo shapes on green consumption, which further demonstrates the relationship between power and logo design.

\subsection{Practical Implications}

Given growing concerns about protecting the environment and sustainable development, identifying effective ways to promote green consumption is of great significance. From an applied perspective, our findings contribute to our understanding of how to increase the likelihood of green consumption, which is relevant to environmental sustainability and numerous companies that offer green products.

First and most importantly, the present research suggests a simple and effective way for firms manufacturing green products to render more green choices by logo design. While most firms have been designed explicitly to promote pro-environmental behaviors (e.g., "protect the environment" appeals) [4,55], our research encourages these firms to implicitly influence consumers' pro-environmental orientation by subtly designing their logos shapes. For example, marketers could employ roundness cues in their logo shapes design in order to motivate green consumption.

Second, the current research provides suggestions about product attributes and appeals types for manufacturers and retailers. In this research, we found the mediating role of self-construal and the moderating role of sense of power in the relationship between logo shapes and green consumption, which indicated the important impact of self-construal and power. Therefore, firms and retailers can also motivate green consumption from the perspective of self-construal and power. For instance, firms could add some cues related to interdependent self-construal, and retailers could incorporate symbols of social relationship into their appeal.

Third, our research also encourages company to conduct market research on their target audiences and collect information of consumers' self-construal and power, which contributes to better market segmentation. If direct targeting of individual consumers is possible, firms could adopt different marketing strategies for different consumer groups [56]. For example, for consumers with interdependent self-construal or low-power, companies should highlight the pro-environmental value of their products; for consumers with independent self-construal or high-power, companies could emphasize the utility value of their products.

\subsection{Limitation and Future Direction}

Our study has some limitations, which in turn warrants a number of avenues for future research. First, our research only focused on one specific aspect of logo design (i.e., angular and circularlogo shapes). There is no denying that most actual brand logos are more complex than logos we used in this research; they usually are composed of several different visual elements (e.g., color, size). For example, recent research found that brand logo location (i.e., high vs. low) has an effect on consumers' purchase intention and willingness to recommend a product [57]. Therefore, future research could explore more visual elements of logos and examine their relationship with green consumption.

Second, as with other experimental study, generalizability of our research can also be increased in some ways. Our study was conducted in China, where self-construal is considered to be predominantly interdependently oriented. Thus, future research is needed to replicate our results in other independently oriented countries. In addition, consumer literature showed that people have green-feminine stereotype, which can influence males' likelihood of adopting green behaviors [58]. Thus, future research of green consumption could consider more demographic variables such as gender, age, and cultural background. Finally, since we only measured consumers' product choice and purchase intention in this study, future research could involve actual green consumption behaviors.

Author Contributions: Conceptualization, L.X. and F.Y.; Data curation, L.X. and F.Y.; Funding acquisition, F.Y.; Methodology, L.X. and F.Y.; Project administration, F.Y.; Supervision, F.Y.; Validation, L.X. and F.Y.; Visualization, F.Y.; Writing - original draft, L.X.; Writing—review \& editing, F.Y. and X.D. All authors have read and agreed to the published version of the manuscript. 
Funding: This research was funded by Major Project of the National Social Science Fund of China, grant number 18ZDA307 and 17ZDA324.

Conflicts of Interest: The authors declare no conflict of interest.

\section{References}

1. Romani, S.; Grappi, S.; Bagozzi, R.P. Corporate socially responsible initiatives and their effects on consumption of green products. J. Bus. Ethics 2016, 135, 253-264. [CrossRef]

2. Toyota Environmental Challenge 2050. Available online: https://global.toyota/en/sustainability/esg/ challenge2050 (accessed on 12 October 2019).

3. Luchs, M.G.; Naylor, R.W.; Irwin, J.R.; Raghunathan, R. The sustainability liability: Potential negative effects of ethicality on product preference. J. Mark. 2010, 74, 18-31. [CrossRef]

4. Yang, D.; Lu, Y.; Zhu, W.; Su, C. Going green: How different advertising appeals impact green consumption behavior. J. Bus. Res. 2015, 68, 2663-2675. [CrossRef]

5. Kim, Y.; Choi, S.M. Antecedents of green purchase behaviour: An examination of collectivism, environmental concern, and PCE. Adv. Consum. Res. 2005, 32, 592-599.

6. Khare, A. Antecedents to green buying behaviour: A study on consumers in an emerging economy. Mark. Intell. Plan. 2015, 33, 309-329. [CrossRef]

7. Park, C.W.; Eisingerich, A.B.; Pol, G.; Park, J.W. The role of brand logos in firm performance. J. Bus. Res. 2013, 66, 180-187. [CrossRef]

8. Di Fabio, A.; Rosen, M.A. Opening the black box of psychological processes in the science of sustainable development: A new frontier. Eur. J. Sustain. Dev. Res. 2018, 2, 47. [CrossRef]

9. Di Fabio, A. The psychology of sustainability and sustainable development for well-being in organizations. Front. Psychol. 2017, 8, 1534. [CrossRef] [PubMed]

10. Di Fabio, A.; Kenny, M.E. Connectedness to nature, personality traits and empathy from sustainability perspective. Curr. Psychol. 2018, 37, 1-12. [CrossRef]

11. Sundar, A.; Noseworthy, T.J. Place the logo high or low? Using conceptual metaphors of power in packaging design. J. Mark. 2014, 78, 138-151. [CrossRef]

12. Chevalier, M.; Mazzalovo, G. Pro Logo: Brands as a Factor of Progress; Springer: New York, NY, USA, 2003.

13. Anastasiou, C.; Keramitsoglou, K.; Kalogeras, N.; Tsagkaraki, M.; Kalatzi, I.; Tsagarakis, K. Can the "Euro-Leaf" logo affect consumers' willingness-to-buy and willingness-to-pay for organic food and attract consumers' preferences? An empirical study in Greece. Sustainability 2017, 9, 1450. [CrossRef]

14. Fajardo, T.M.; Zhang, J.; Tsiros, M. The contingent nature of the symbolic associations of visual design elements: The case of brand logo frames. J. Consum. Res. 2016, 43, 549-566. [CrossRef]

15. Bossel, V.; Geyskens, K.; Goukens, C. Facing a trend of brand logo simplicity: The impact of brand logo design on consumption. Food Qual. Preference 2019, 71, 129-135. [CrossRef]

16. Zhang, Y.; Feick, L.; Price, L.J. The impact of self-construal on aesthetic preference for angular versus rounded shapes. Pers. Soc. Psychol. B. 2006, 32, 794-805. [CrossRef] [PubMed]

17. Jiang, Y.; Gorn, G.J.; Galli, M.; Chattopadhyay, A. Does your company have the right logo? How and why circular-and angular-logo shapes influence brand attribute judgments. J. Consum. Res. 2015, 42, 709-726. [CrossRef]

18. Chattopadhyay, A.; Gorn, G.J.; Darke, P. Differences and similarities in hue preferences between Chinese and Caucasians. In Sensory Marketing: Research on the Sensuality of Products; Aradhna, K., Ed.; Routledge Academic: New York, NY, USA, 2010; pp. 219-240.

19. Labrecque, L.I.; Milne, G.R. Exciting red and competent blue: The importance of color in marketing. J. Acad. Market. Sci. 2012, 40, 711-727. [CrossRef]

20. Labrecque, L.I.; Patrick, V.M.; Milne, G.R. The marketers' prismatic palette: A review of color research and future directions. Psychol. Mark. 2013, 30, 187-202. [CrossRef]

21. Hagtvedt, H. The impact of incomplete typeface logos on perceptions of the firm. J. Mark. 2011, 75, 86-93. [CrossRef]

22. Cian, L.; Krishna, A.; Elder, R.S. This logo moves me: Dynamic imagery from static images. J. Mark. Res. 2014, 51, 184-197. [CrossRef] 
23. van Rompay, T.J.; Pruyn, A.T.; Tieke, P. Symbolic meaning integration in design and its influence on product and brand evaluation. Int. J. Des. 2009, 3, 19-26.

24. Janiszewski, C.; Meyvis, T. Effects of brand logo complexity, repetition, and spacing on processing fluency and judgment. J. Consum. Res. 2001, 28, 18-32. [CrossRef]

25. Kim, J.; Yoon, C.; Gonzalez, R. Product expression and self-construal: Downstream effects of connected shapes on social connectedness. In Proceedings of the 12th International Design Conference, Dubrovnik, Croatia, 21-24 May 2012.

26. Fitzsimons, G.M.; Chartrand, T.L.; Fitzsimons, G.J. Automatic effects of brand exposure on motivated behavior: How apple makes you "think different". J. Consum. Res. 2008, 35, 21-35. [CrossRef]

27. Berlyne, D.E. Psychological aesthetics. Int. J. Psychol. 1976, 11, 43-55. [CrossRef]

28. Griskevicius, V.; Tybur, J.M.; van den Bergh, B. Going green to be seen: Status, reputation, and conspicuous conservation. J. Personal. Soc. Psychol. 2010, 98, 392-404. [CrossRef] [PubMed]

29. Penner, L.A.; Dovidio, J.F.; Pilavin, J.A.; Schroeder, D.A. Prosocial behavior: Multilevel perspectives. Ann. Rev. Psychol. 2005, 56, 365-392. [CrossRef] [PubMed]

30. Markus, H.R.; Kitayama, S. Culture and the self: Implications for cognition, emotion, and motivation. Psychol. Rev. 1991, 98, 224-253. [CrossRef]

31. Singelis, T.M. The measurement of independent and interdependent self-construals. Personal. Soc. Psychol. B. 1994, 20, 580-591. [CrossRef]

32. Briley, D.A.; Wyer, R.S. The effect of group membership salience on the avoidance of negative outcomes: Implications for social and consumer decisions. J. Consum. Res. 2002, 29, 400-415. [CrossRef]

33. Kühnen, U.; Oyserman, D. Thinking about the self influences thinking in general: Cognitive consequences of salient self-concept. J. Exp. Soc. Psychol. 2002, 38, 492-499. [CrossRef]

34. Lin, Z.; Han, S. Self-construal priming modulates the scope of visual attention. Q. J. Exp. Psychol. 2009, 62, 802-813. [CrossRef]

35. Zhu, R.; Argo, J.J. Exploring the impact of various shaped seating arrangements on persuasion. J. Consum. Res. 2013, 40, 336-349. [CrossRef]

36. Walsh, M.F.; Winterich, K.P.; Mittal, V. How re-designing angular logos to be rounded shapes brand attitude: Consumer brand commitment and self-construal. J. Consum. Mark. 2011, 28, 438-447. [CrossRef]

37. Kitayama, S.; Park, H.; Sevincer, A.T.; Karasawa, M.; Uskul, A.K. A cultural task analysis of implicit independence: Comparing North America, Western Europe, and East Asia. J. Personal. Soc. Psychol. 2009, 97, 236-255. [CrossRef] [PubMed]

38. Kitayama, S.; Park, J. Error-related brain activity reveals self-centric motivation: Culture matters. J. Exp. Psychol. Gen. 2014, 143, 62. [CrossRef] [PubMed]

39. Ashton-James, C.; Van Baaren, R.B.; Chartrand, T.L.; Decety, J.; Karremans, J. Mimicry and me: The impact of mimicry on self-construal. Soc. Cognit. 2007, 25, 518-535. [CrossRef]

40. Arnocky, S.; Stroink, M.; DeCicco, T. Self-construal predicts environmental concern, cooperation, and conservation. J. Environ. Psychol. 2007, 27, 255-264. [CrossRef]

41. Chuang, Y.; Xie, X.; Liu, C. Interdependent orientations increase pro-environmental preferences when facing self-interest conflicts: The mediating role of self-control. J. Environ. Psychol. 2016, 46, 96-105. [CrossRef]

42. Keltner, D.; Gruenfeld, D.H.; Anderson, C. Power, approach, and inhibition. Psychol. Rev. 2003, 110, $265-284$. [CrossRef]

43. Magee, J.C.; Galinsky, A.D. Social hierarchy: The self-reinforcing nature of power and status. Acad. Manag. Ann. 2008, 2, 351-398. [CrossRef]

44. Anderson, C.; John, O.P.; Keltner, D. The personal sense of power. J. Pers. 2012, 80, 313-344. [CrossRef]

45. Galinsky, A.D.; Gruenfeld, D.H.; Magee, J.C. From power to action. J. Personal. Soc. Psychol. 2003, 85, 453-466. [CrossRef] [PubMed]

46. Galinsky, A.D.; Rucker, D.D.; Magee, J.C. Power: Past findings, present considerations, and future directions. In APA Handbook of Personality and Social Psychology; Mikulincer, M., Shave, P.R., Eds.; American Psychological Association: Washington, DC, USA, 2015; Volume 1, pp. 421-460.

47. Rucker, D.D.; Dubois, D.; Galinsky, A.D. Generous paupers and stingy princes: Power drives consumer spending on self and others. J. Consum. Res. 2011, 37, 1015-1029. [CrossRef]

48. Anderson, C.; Berdahl, J.L. The experience of power: Examining the effects of power on approach and inhibition tendencies. J. Personal. Soc. Psychol. 2002, 83, 1362-1377. [CrossRef] 
49. Galinsky, A.D.; Magee, J.C.; Gruenfeld, D.H.; Whitson, J.A.; Liljenquist, K.A. Power reduces the press of the situation: Implications for creativity, conformity, and dissonance. J. Personal. Soc. Psychol. 2008, 95, 1450-1466. [CrossRef]

50. Hayes, A.F.; Preacher, K.J.; Myers, T.A. Mediation and the estimation of indirect effects in political communication research. In Sourcebook for Political Communication Research: Methods, Measures, and Analytical Techniques; Bucy, E.P., Holbert, R.L., Eds.; Routledge: New York, NY, USA, 2011; pp. 434-465.

51. MacKinnon, D.P.; Fairchild, A.J.; Fritz, M.S. Mediation analysis. Ann. Rev. Psychol. 2007, 58, 593-614. [CrossRef]

52. Anderson, C.; Galinsky, A.D. Power, optimism, and risk-taking. Eur. J. Soc. Psychol. 2006, 36, 511-536. [CrossRef]

53. Di Fabio, A.; Tsuda, A. The psychology of harmony and harmonization: Advancing the perspectives for the psychology of sustainability and sustainable development. Sustainability 2018, 10, 4726. [CrossRef]

54. Zhang, Y.; Ao, J.; Deng, J. The influence of high-low power on green consumption: The moderating effect of impression management motivation. Sustainability 2019, 11, 4287. [CrossRef]

55. Edinger-Schons, L.M.; Sipilä, J.; Sen, S.; Mende, G.; Wieseke, J. Are two reasons better than one? The role of appeal type in consumer responses to sustainable products. J. Consum. Psychol. 2018, 28, 644-664. [CrossRef]

56. Chan, K. Market segmentation of green consumers in Hong Kong. J. Int. Consum. Mark. 2000, 12, 7-24. [CrossRef]

57. Dong, R.; Gleim, M.R. High or low: The impact of brand logo location on consumers product perceptions. Food Quality and Preference. Food Qual. Preference 2018, 69, 28-35. [CrossRef]

58. Brough, A.R.; Wilkie, J.E.B.; Ma, J.; Isaac, M.S.; Gal, D. Is eco-friendly unmanly? The green-feminine stereotype and its effect on sustainable consumption. J. Consum. Res. 2016, 43, 567-582. [CrossRef]

(C) 2020 by the authors. Licensee MDPI, Basel, Switzerland. This article is an open access article distributed under the terms and conditions of the Creative Commons Attribution (CC BY) license (http://creativecommons.org/licenses/by/4.0/). 